\title{
Perception of nursing workers on the care of hypertension in older adult
}

\author{
Percepção de trabalhadores de enfermagem sobre o cuidado ao idoso portador de hipertensão arterial sistêmica
}

Percepción de trabajadores de enfermería sobre la atención del adulto mayor portador de hipertensión arterial sistémica

\section{Rosimeire Fontes de Queiroz' ORCID: 0000-0003-0920-7596}

Angela Maria Alvarez" ORCID: 0000-0002-2622-3494

Luana Jordana Morais' ORCID: 0000-0001-9334-3069

Richardson Augusto Rosendo da Silva' ORCID: 0000-0001-6290-9365

'Universidade Federal do Rio Grande do Norte. Natal, Rio Grande do Norte, Brazil. "Universidade Federal de Santa Catarina. Florianópolis, Santa Catarina, Brazil.

How to cite this article: Queiroz RF, Alvarez AM, Morais LJ, Silva RAR. Perception of nursing workers on the care of hypertension in older adult. Rev Bras Enferm. 2019;72(Suppl 2):3-13. doi: http://dx.doi.org/10.1590/0034-7167-2016-0681

\section{Corresponding Author}

Rosimeire Fontes de Queiroz

E-mail: roseerai@hotmail.com

\section{ABSTRACT}

Objective: To understand how nursing workers perceive care of hypertension (HBP) in older adult within the scope of the Family Health Strategy. Method: A qualitative descriptive study carried out in the city of Natal/RN, with 20 nursing workers providing care to older adults with HBP. The data were obtained through a semi-structured interview and analysed by the Thematic Analysis, based on the theoretical support of the integrality, using Atlas.ti 7.0 software. Results: The elements found as facilitators were: territorialization, partnerships, professional proactivity and the user's bond with the team. Among those found as barriers were: disease-centered care; academic education based on the biomedical model; lack of inter-sectorality and discontinuity of care in the care network. Final considerations: Nursing workers perceive that health institutions lack articulated and innovative practices that incorporate new paradigms focused on integrality of care.

Descriptors: Primary Health Care; Health Services for the Aged; Chronic Disease; Delivery of Health Care; Family Nurse Practitioners.

\section{RESUMO}

Objetivo: Compreender como os trabalhadores de enfermagem percebem o cuidado ao idoso portador de hipertensão arterial sistêmica (HAS) no âmbito da Estratégia Saúde da Família. Método: Estudo descritivo, de natureza qualitativa, realizado no município de Natal/RN, com 20 trabalhadores de enfermagem que prestam assistência a idosos portadores de HAS. Os dados foram obtidos através de entrevista semiestruturada e tratados pela Análise Temática. Estão fundamentados no suporte teórico da integralidade, com auxílio do software Atlas.ti 7.0. Resultados: Foram identificados como elementos que favorecem o cuidado: territorialização, parcerias, proatividade dos profissionais e vínculo do usuário com a equipe. Entre os que dificultam o cuidado: assistência centrada na doença, formação acadêmica pautada no modelo biomédico, inexistência de intersetorialidade e descontinuidade do cuidado na rede assistencial. Considerações Finais: Os trabalhadores de enfermagem percebem que as instituições de saúde carecem de práticas articuladas e inovadoras que incorporem novos paradigmas com foco na integralidade do cuidado.

Descritores: Atenção Primária à Saúde; Serviços de Saúde para Idosos; Doença Crônica; Assistência à Saúde; Enfermeiras de Saúde da Família.

\section{RESUMEN}

Objetivo: Comprender la percepción que los profesionales de enfermería tienen sobre la atención de los adultos mayores con hipertensión arterial sistémica (HTA) en el ámbito de la Estrategia de Salud Familiar. Método: Se trata de un estudio descriptivo y cualitativo llevado a cabo en la ciudad de Natal, Rio Grande del Norte, con 20 enfermeros que atienden a personas mayores con HTA. Los datos se obtuvieron mediante entrevistas semiestructuradas y fueron tratados mediante Análisis Temático, basado en el soporte teórico de la integridad, con la ayuda del software Atlas.ti 7.0. Resultados: Se identificaron como favorecedores de la atención los siguientes elementos: territorialización, alianzas, proactividad de los profesionales y vinculación del usuario con el equipo y entre los entorpecedores: atención centrada en la enfermedad, formación académica basada en el modelo biomédico, ausencia de intersectorialidad y discontinuidad de la atención en la red asistencial. Consideraciones Finales: Los trabajadores de enfermería perciben que las instituciones de salud carecen de prácticas articuladas e innovadoras que puedan incorporar nuevos paradigmas centrados en la integralidad de la atención.

Descriptores: Atención Primaria de la Salud; Servicios de Salud para Adultos Mayores; Enfermedades Crónicas; Atención a la Salud; Enfermeros de Salud Familiar. 


\section{INTRODUCTION}

Hypertension (HBP) is an important modifiable cardiovascular risk factor, being considered one of the most important public health problems. A disease that arises mainly in middle age and in old age, hypertension is generally associated with the interaction of genetic factors and lifestyle ${ }^{(1)}$.

In Brazil, it is estimated that the prevalence of hypertension in the elderly exceeds $50 \%$, a rate also high in international contexts ${ }^{(2)}$. In the United States of America, about $30 \%$ of the total adult population is affected by HBP, whereas in individuals aged 60 years or over, this percentage increases to $65 \%$. Due to its high prevalence and its causal relationship with all cardiovascular diseases, HBP is the main risk factor for mortality worldwide ${ }^{(3)}$.

Older adult with HBP face multidimensional problems that affect their health and, consequently, their quality of life. In this perspective, it is fundamental that health professionals commit themselves to offer care to older adults with hypertension that prioritize aspects that favor an adaptive individual process in the prevention and control of chronic diseases inherent in the aging process. Thus, attention to the elderly is a major challenge, requiring a global, interdisciplinary and multiprofessional approach that contributes so that, despite the progressive limitations that may occur, it is possible to discover strategies for aging with a high level of quality(4).

Good health care assumes the patient's trust and bond with the health professional, built in the host and throughout the caring process. This management should be initiated at the door of entry and accompany the patient throughout his health system trajectory along aging ${ }^{(5)}$.

In the care of the elderly person with hypertension, the emphasis on health promotion rests on modifying their lifestyle, adapting the possibilities of the elderly with this disease to the reality of their experience, the transformation of individual and collective processes, and decision-making to develop actions predominantly favorable to quality of life. Thus, the relationships between professionals and the elderly with this disease demand renewed tools and creativity exercises in their educational process. In general, the elderly in chronic conditions require different care, involving a range of diversified and long-lasting actions ${ }^{(6)}$.

However, in the daily life of the health units, there are few or almost no offer of actions that promote the health of the elderly with HBP. Most often, the elderly are labeled with the name of their pathology and are only assisted if they develop hypertension or diabetes or another related disease that fits the list of activities always aimed at treating the disease already installed, without focusing on preventing illness ${ }^{(7)}$.

The central focus of health care for the older adult with hypertension should be primary care, through the Family Health Strategy (FHS), which is one of the entry points of the Unified Health System (SUS - Sistema Único de Saúde). At this level of care, it is possible to monitor their health conditions and detect early conditions. Thus, the approach used with older adults with HBP imposes new care paradigms, having as a fundamental element the emphasis on functional capacity, which makes it imperative to train health professionals aware of the country's new demographic and epidemiological scenario ${ }^{(7-8)}$.
Studies carried out in the field of care for the older adult with HBP demonstrate that this practice has been structured according to the demands that emerge in the daily life of this population, although the care is still focused on the curative aspect, giving priority to medication control and treatment. These studies also indicate the need to structure the work process in the FHS in order to combine programmatic activities and individualized therapeutic projects, interventions that promote health while reducing risks and, at the same time, increasing the degree of autonomy of the older adult with this disease,so they know how to live with their limitations and disabilities (4-5,9-11). $^{\text {. }}$

In this sense, it is believed that the study about the way nurses perceive the elderly person with HBP in the FHS can provide contextualization about the health field, arousing looks to affective, symbolic and subjective aspects, contributing to a professional practice focused for education and health promotion by making it more compatible with the actions of care and with the specific demands of this age group. It is also hoped, with this work, to contribute to the reorientation of health to the elderly person with $\mathrm{HBP}$ in the scope of Primary Health Care (PHC), encouraging new research in the area.

Thus, the present study is justified by the need to know the perceptions of nursing workers about the care of elderly people with HBP in FHS. In this sense, the singularities highlighted by the interviewees in the present research may reveal a rich universe of possibilities to understand how this care is developed in the FHS territory investigated, essential to expand the discussions of the subject in other scenarios in Brazil, with a view to improving policies public health in the elderly.

Thus, we have the following guiding question: What are the perceptions of nursing workers about the care provided to old adults with hypertension in the FHS?

\section{OBJECTIVE}

To understand how nurses perceive care provided to older adults with hypertension in the FHS.

\section{METHOD}

\section{Ethical aspects}

The research project was approved by the Research Ethics Committee of the Federal University of Santa Catarina (UFSC), by the protocol no 551.146 e CAAE no 25702013.3.0000. 0121. Before starting the data collection, the study participants were clarified about the purpose of the research and read the Informed Consent Form (TCLE), which was signed by them, expressing their agreement to participate, so that the research was finally started.

Fieldwork was conducted by the student researcher of the doctorate of the present study. The researcher's commitment and responsibility for preserving the identity of the participants and the confidentiality of the information were elucidated. The interviewees were also informed about how the research would be conducted, about the ethical principles that would be followed during the interview, such as: presentation; explanation of the research motives; importance of ensuring anonymity, secrecy 
of the answers, emphasizing that the participants would be free to interrupt and ask for clarification, and could also, if they wish, leave the research at any time without any loss.

\section{Study design}

Descriptive study of qualitative nature.

\section{Setting}

The city of Natal/RN is administratively divided into five Health Districts (North 1, North 2, South, East and West), with defined areas of coverage. Each district has its headquarters and is responsible for monitoring the performance of care provided by health teams to users in their area. The place chosen to carry out the study was the West Sanitary District of Natal/RN, which maintains: 12 Family Health Units (FHU), a polyclinic, two specialized mental health clinics, two Psychosocial Care Centers (CAPS), CAPS I and CAPS II, with day care (Monday to Friday) of adults with mental disorders, a Mobile Emergency Care Service (SAMU), two mixed units and a child care emergency.

\section{Data sources}

During the data collection period, 230 nursing professionals were enrolled in the FHS of the West Sanitary District of Natal, Northeastern region of Brazil. Twenty nursing workers from the West Sanitary District of Natal, RN, participated in the study. It should be noted that the saturation of the discourses was taken into account for the selection of the number of participants in the present study.

\section{Study periods}

Data were collected from March to July 2014 through a semistructured interview with each of the participants individually.

\section{Inclusion and exclusion criteria}

The following inclusion criteria were delineated: being a nursing professional and working for more than a year at the FHS. On the other hand, those excluded were: retired professionals, on medical leave, maternity leave and on leave. The semi-structured interview was conducted by a single investigator, in the work place, in a reserved room, with an average duration of 30 minutes, previously scheduled with the Nursing Workers of the Family Health Units (USF) according to availability. The interviewees' speeches were recorded on a digital audio recorder.

\section{Methodological procedures}

The data were analyzed through the technique of Content analysis, in the Thematic modality ${ }^{(12)}$, using ATLAS.ti version 7.0. The software allows indexing non-numeric data and theorizing about them, facilitating qualitative analysis. In the analysis process, these steps were followed: reading and re-reading the interviews, selecting and coding content and grouping similar codes into categories. The Thematic Analysis is defined as a set of techniques of communication analysis with the aim of obtaining, through systematic procedures and description of the content of the messages, indicators (quantitative or not) that allow to infer knowledge regarding the conditions of production/reception (inferred variables) of these posts. The organization of the content comprises the following phases: data coding; categorization of data; and interaction of the thematic nuclei ${ }^{(12)}$. The analysis began with the reading and re-reading of the interviews already transcribed in text, trying to understand how the nursing workers perceive the care to the elderly person with HBP in FHS.

\section{Theoretical-methodological framework}

The theoretical support used was the integrality, constitutional and doctrinal principle of SUS support, considered the greatest challenge for managers and health professionals. To think in integrality is to think of comprehensive care, from health promotion to healing and rehabilitation ${ }^{(13)}$. Thus, the SUS organization should be responsible for the continuity of care considering the general needs of the people as a whole, not limited to the treatment and/ or prevention of their complications. New needs arise in adult life, and the contingencies of such living result in new needs to be recognized, managed and cared for by health professionals. The look of wholeness invites us to think about how complex health care is and how difficult it is to achieve this ideal.

\section{RESULTS}

Twenty women working in the Family Health Units of Natal, in the West Sanitary District, participated in the study, where they collaborated in the integration of teaching and service in the curricular stages of the Federal University of Rio Grande do Norte (UFRN). They were in the age group between 40 and 49 years old, had higher education (45.4\%) and high school education (54.6\%) and had worked in the sector on average for 12 years.

In the thematic modality, the content analysis of the interviews made it possible to define the Central Thematic Unit entitled "perceptions about the health care provided to older adults with HBPin FHS transmitted by nursing workers", from which emerged the categories from interviewee' own discourses: Elements that favor the care of hypertension in older adults and Processes that hinder health care of hypertension in older adults. From the first, three subcategories emerged: 1) The territorial context; 2) Partnerships and proactivity of professionals in care for the older adult; 3) The user's bond with the team. The following subcategories emerged from the second category: 1) Disease-centered care; 2) Academic training based on the biomedical model; 3) Inexistence of Intersectoriality; 4) Discontinuity of care in the care network.

In search of nuclei of meaning to obtain the empirical categories and subcategories, the corpus of analysis was elaborated at the end of each transcription of the interviews. To do so, the transcription of speeches was read and re-read exhaustively and then analyzed each one, guided by the object of study.

\section{The territorial context}

In order to assess the health situation in the territory, the living space where the community is in permanent movement 
and transformation, it is important that the Family Health Team monitor it, following the actions and results of its practice on the health situation of the population, especially older adults with HBP, as these participants report:

I think that as the nurse is responsible for that territory where I work, I have to accompany the elderly with HBP, to know how they are being treated, how they are being followed-up, if they are medicated, how they are feeding themselves; these follow-ups that we do every day in the territory [...] in this territory it is possible to create bond and affection with this elderly person. (P16)

The health agent is a very important piece, because it is he who identifies the elderly with systemic arterial hypertension in the territory; he knows not only the patient, but also the family, the family history and how these elderly people live, their customs, their beliefs; then a bond is created that facilitates care... over time a relationship of trust is created [...] both the elderly and the worker become responsible for care. (P17)

In this context, these lines allow nursing workers to know the subjectivity of the subjects, favoring them to perceive important elements present in beliefs, attitudes, values and information, according to subjective experiences of communication between these subjects. In this perspective, perceptions constitute a reality that is given a value in order to preserve the social construction of the experience around the control of the Elderly HBP in the FHS.

\section{Partnerships and proactivity of professionals in care for the older adult}

The following excerpts show how a symbolic organization on which the different practices and social relations are developed in the control of the older adult, nursing workers, institution and community represents a subjective production.

Here in the health unit, with the programs we have,... manual labor, quarterly parties; When they finish the year, we join January, February, March and celebrate. There's the carnival party, there's a schedule. And what do we do? We make partnerships [...] We ask each worker to adopt an elderly person with HBP and we go out asking for money, two, three Reais, here in the community. Nursing care is this, we go beyond it, we have to be proactive. (P19)

We got used here to work with donations to make a bazaar; has a treasurer, sometimes we earn five hundred, six hundred reais, and this money is used for the snack of the elderly people with systemic arterial hypertension... we have to be proactive. (P19)

In the social part is where we can go, we work with the Center for Rehabilitation and Social Assistance and in this way, we can do the work with partnerships. We call the family of the elderly with systemic arterial hypertension, we talk. It has a partnership with some supermarkets and we distribute, fortnightly or monthly, for each family of these very needy, a small truck. (P19)

In this sense, it is known that the creation of healthy spaces in communities, territories and families depends on projects and actions aimed at promoting health. It is understood that health promotion is a cross-cutting strategy that gives visibility to factors that put the health of the population at risk and the differences between needs, territories and cultures present in our country, aiming at the creation of mechanisms that reduce situations of vulnerability, defending equity and incorporating participation and social control in the management of public policies.

It should be noted that the way of life of elderly people with HBP is influenced by their conceptions of life, beliefs, values and knowledge, variables that are part of the family or collective culture to which they belong. In such a scenario there is a confluence of multiple social actors, and it is important to emphasize the dialogue between professionals, the elderly, families and the community, encouraging them to develop potentialities, stimulating them and helping them to live well with their chronic condition; integrating them as political and social subjects, acting proactively in the elaboration and participation of strategies that aim at more satisfactory living and health conditions, seeking partnerships and intersectoral actions to improve health, education, housing, income and leisure, among others.

\section{The user's bond with the team}

The health service must organize itself to assume its central function of welcoming, listening and offering a positive response, capable of solving health problems and of alleviating damages and suffering, or being responsible for the response, even if it is offered in other points of attention of the network.

Proximity and the capacity for care, bonding and accountability are fundamental to consolidate the primary care as the first contact and the preferential entrance door of the care network. These contents corroborate the nursing workers' statements of the study when they affirm, in their statements, the co-responsibility established by the members of the FHS team with the older adult with HBP in their assigned areas:

Family Health Strategy came in this direction, to create a network, to form bonds of responsibility and co-responsibility, both from the team to the community and from the community to the team and this applies to the elderly people with $\mathrm{HBP}[. .$.$] the nursing approach$ is very close to the elderly and even more so if he or she has some chronic illness... listening and welcoming the elderly person with $H B P$ is very important to create $a$ bond and help them in adhering to treatment [...] with this network, it becomes easier to develop individualized follow-ups. (P15)

The health agent is also very important because we charge and they bring the elderly people with systemic arterial hypertension. It is the agents who have the greatest bond with the community [...] with the formation of the bond if we can promote a more comprehensive care [...] in the meetings we are always stressing that we have this social responsibility with them, because we are also responsible for the elderly caregivers with HBP. (P21)

\section{Disease-centered care}

In this subcategory, nursing workers emphasized that they perceive the importance of providing comprehensive care to older adult with hypertension, although they reinforce their view on biological dimensions, recognizing the need to broaden the social, cultural, psychological and environmental dimensions of the services offered, such as show the following statements: 
In promoting the health of the elderly with $\mathrm{HBP}$, they should have leisure time. They sit in the chair by day and by night, have no leisure time, no activities. Here we do not offer this to them, only to those who can walk, can move; but for those who cannot, there is no alternative [...] as we do not have alternatives, the care comes only to the transcription of medical prescriptions and verification of the blood pressure, that is, the focus is only the disease. (P22)

If you need to take a ride for the elderly with systemic arterial hypertension, you have to go after the car; if the entrance is paid, you that have to go behind to obtain exemption of that payment; if you want to offer a snack, you have to bring this snack, get your money, your salary to make a snack... we end up just treating the disease and forget about other important aspects. (P5)

\section{Academic training based on the biomedical model}

When talking about their perceptions about their practice with older adult with HBP, the nursing workers in the study criticize the biomedical model.

The physician gives that prescription to the elderly person with HBP to receive three months of medication in the popular pharmacies. And this also helps them keep distance from the health unit, because he/she registers at the pharmacy to get the medication and thus does not participate in other activities offered in the unit. So, the assistance comes down to coming to the doctor visit to get the prescription every three months. We still follow the biomedical model, making it difficult to understand the process of illness of the individual [...] many of the nursing do not consider the conception of integrality of health care. (P16)

With regard to care for elderly people with $\mathrm{HBP}$, it is more curative, we know that patients come here to the doctor; they get a prescription, but... I think it's very much on top of the problem that the patient brings. It is our fault that our training was centered on the biomedical model... the search for the integral care of the elderly with HBP requires the disruption of the biomedical model [...] when their training is not a biologist, you can integrate care of the elderly with $H B P$, their relatives and caregivers, and in coping with other situations such as loss of functional capacity and even mourning. (P5)

This is not the fault of the people, it's the fault of the academy, it's the fault of the Ministry of Health, which always focuses on diseases. In college I have never studied anything about geriatrics and gerontology... social, economic, and subjective aspects of determining the health-disease process are not investigated when their background is biologist. The professionals here are still very biologists. The experience with the elderly patient with HBP here in the area where I work is very worrying, we have some with functional dependence already very advanced, because we usually find some who live alone or that the relatives do not have time to take care. (P4)

\section{Inexistence of Intersectoriality}

The following results demonstrate the perceptions of nursing workers that consider the health network disjointed. Events listed here and that constituted this category demonstrate the difficulties of hypertension in older adults in the use of the public health service when seeking support for the treatment of chronic disease in the health care network.
When you think about the difficulties of the elderly with hypertension without cardiovascular risks, it is easier for us to control ourselves. However, when he/she needs a specialist's visit, this breaks down a little [...] lack of articulation between the different services and actions related to the care of elderly people with $\mathrm{HBP}$ [...] also note the inexistence of actions integrated in care of elderly people with $H B P[. .$.$] the lack of strategies to solve the problems of elderly people$ with hypertension in a creative and intersectoral way are obstacles to the care. (P6)

In practice I do not see the adoption of integrated publichealth policies, supported by intersectoral actions [...] lack of integration between different areas and different professionals of the FHS in the care of elderly people with HBP. Often you are faced with situations where you cannot give a direction. When, for example, the elderly with systemic arterial hypertension were not able to schedule or carry out a medium or high complexity consultation and often spend months or years without achieving and could suffer even a complication because they were not given the guarantee of care for the average and high complexity, which escapes our attention capacity in the basic unit... intersectoral actions such as increased levels of physical activity of elderly people with HBP are fundamental, but we do not have time for this. (P15)

Thus, it was verified that older adult with hypertension and with greater needs for health care seek care in other services of reference of basic care, however, the unit is not prepared to provide adequate care to this population due to lack of an articulated network continuation of care in other areas of the system.

According to the perception of nursing workers, the slowness of public service attendance in medium and high complexity may aggravate the health problem of the user. The situation becomes even more difficult when it comes to scheduling consultation with medical specialists because, depending on the specialty, the user usually waits a long period to be attended to.

\section{Discontinuity of care in the care network}

In the perception of nursing workers, there is a concern about the interruption of the follow-up of older adult with hypertension by a health team or by a professional that composes it, whether it is performed individually at the Basic Health Unit (BHU), in meetings with a group of hypertensions in older adults through home visits. In addition to impairing the bonding and trust relationship established by the team with this older adult and their family, the change of the professional can still bring the problem of treatment discontinuity. This situation impairs the care given to older adult with HBP, as the following statement reveals:

The lack of the medical professional in our reality is complicated! For other professionals not so much, but there is a lot of physicians' turnover. I see this as a negative thing for the care of the elderly with hypertension, since there is a break in the activities in progress. Here, when the physician is getting to know that community, it's time to go and a new doctor comes. (P16)

The maintenance of the functional capacity of the older adult with hypertension is also a challenge for the health services and their professionals. In this context, the diversity of processes in $\mathrm{PHC}$ and the real inclusion of this older adult health require a restructuring of the health care network. 
And leaving the health unit to other sectors within the secretariat is also difficult... the care is still segmented and disjointed... care is not interconnected to a more complex service network. It is difficult for you to refer elderly people with HBP to a geriatrician, it is difficult to transport this patient because he/she does not have a car, the service does not have a car; even had to do physiotherapy, but today we do not have it any more... there are still many barriers between the different levels of attention. (P16)

The reference and counter reference does not work. You have an elderly person with systemic arterial hypertension who needs an evaluation today, and a month later it has not been evaluated; and a patient who needs vascular evaluation cannot wait a month; it will worsen and will be hidden, because the network was not guaranteed and it is beyond our competence, both technically and locally. [...] The absence of a comprehensive health care network for the elderly is the greatest challenge in the care of elderly people with $H B P$... the network is disorganized, support services are lacking, services are lacking, specialized services are insufficient. (P15)

\section{DISCUSSION}

Territorialisation is one of the basic assumptions of the work in the FHS, making it possible to recognize the living conditions and the health situation of the population in an area of coverage, as well as the population risks and the potential of the territories. The dimension "sanitary responsibility" refers to the role that the teams must assume in their territory of action, considering environmental, epidemiological, cultural and socioeconomic issues, contributing, through health actions, to reduce risks and vulnerabilities ${ }^{(14)}$.

In the present study, the territory constitutes a space to build bond, affectivity and trust between the older adult with $\mathrm{HBP}$ and nursing workers ${ }^{(15)}$, allowing them to deepen the process of coresponsibility for health built over time, besides carrying in itself a therapeutic potential.

In this territory, nurses can qualify care for the older adult with HBP in the scope of FHS by carrying out actions that favor integrality of care, such as: health promotion (educational actions with an emphasis on lifestyle changes, reduction of risk factors and production of educational material); training of professionals; referral to other professionals, when indicated; monitoring, information, evaluation and monitoring of hypertension and its risk factors, indispensable for the organization of the response of the services, in an integrated way to the health information systems, adopting measurable and specific indicators; individual and operational assistance actions; multidimensional assessment of functional capacity, physical health, cognitive function, emotional state and socio-environmental conditions; preparation and implementation of care plans, participation in research projects and management of HBP control programs ${ }^{(16)}$.

The partnerships and proactivity of nursing workers were also perceived in the present study as elements that favor the care of older adults with HBP in the FHS. The contemporary work scenario has been increasingly demanding, stimulating a professional standard of a worker who has become more qualified, proactive and enterprising everyday ${ }^{(17)}$.

In the area of nursing, this perspective is not different, and there is a need for nursing workers to see differentiated, qualified care with a view to the best care practices, which refers to the critical reflection about the actions they develop, as well as respect for its purposes and how these actions can be improved. Given the specificities in the elderly care practices within the scope of the FHS, nursing professionals are expected to identify their health needs in order to contribute to the preservation of the elderly person's functional capacity, innovating and implementing their work ${ }^{(17)}$.

The proactive action of nursing workers was seen as an opportunity to go beyond the disease and to value complaints and subjective aspects of hypertension in older adults, showing concern about the effectiveness of care and actions developed. In this perspective, emphasis is placed on the relevance of actions that encompass the multiple dimensions of care, as well as the importance of strategies that consider multi and interdisciplinarity, and the non-fragmentation of processes, aiming at the continuous improvement of practices ${ }^{(18)}$.

The health promotion presents itself as a fundamental tool for the care of hypertension in older adults. It should be based on comprehensive care that promotes the development of autonomy and self-care, active aging, minimizing the risk factors and possible complications of $\mathrm{HBP}^{(19)}$. But to achieve success in the prevention and control of HBP, it is necessary to develop collaboration outside the health sector through the establishment of partnerships. In this sense, nurses should seek to encourage the elderly, through representatives of the community and civil society, to develop community activities. The creation of alloys and associations of HBP carriers, in partnership with the FHS, are examples of strategies that can increase the patient's adherence to the treatment instituted.

In addition, comprehensive care for the elderly with HBP should cover all levels of action, articulating actions of the care line in the field of macro and micropolitics. In the field of macropolitics, there are regulatory actions, intersectorial articulations and organization of the service network and health system (strengthening of multidisciplinary teams), as well as support for decision systems (evidence-based guidelines, training of professionals) and clinical information system. In the field of micropolitics, team performance in the line of care and attachment and accountability, with longitudinal monitoring and the production of user autonomy ${ }^{(6-7)}$.

In the field of health promotion, the idea of building healthier environments in the family space involves, in addition to medical technology, recognition of the therapeutic potential of family relationships and existing social networks in the community, such as neighbors, co-workers, religious groups, self-help groups and so many others ${ }^{(16)}$.

In addition, the health problems of older adults with HBP require the care model to be directed towards this age group, which is more efficient and effective, in order to develop actions involving all levels of care and to maintain a well-designed flow of education, promotion of health, delaying diseases, weaknesses and reducing health inequities ${ }^{(20)}$.

Another element unveiled in the study as essential for the care of hypertension in older adults in FHS was the patient's bond with the team. This is a fundamental element in the feeling of protection and security against health needs. When looking at changes in the model of health care, the Ministry of Health proposes the FHS and defines for its direction the establishment of bonds 
and the creation of bonds of commitments and responsibilities between population and health professionals ${ }^{(21)}$.

The present study evidenced the existence of an approximation between users and nursing workers, involving affectivity, help, respect, trust and co-responsibility. The rotation of the medical professional was pointed out as a reason to break this link built in the meetings between professional and user, impairing the continuity of the initiated and therapeutic activities instituted, corroborating with the results of other studies $(4,9,15,18)$. In view of this, it is possible to say that the occurrence of the bond is capable of increasing the effectiveness of health actions and favoring the participation and involvement of the subjects in the care delivery. Once the team and the population maintain close relationships and continuous contact within and outside the service, the bond is more easily consolidated, enabling the identification of the most appropriate needs and responses ${ }^{(22)}$.

In this sense, the linkage established between nursing workers of the FHS and the elderly person with SA strengthens trust in services. And this relationship is fundamental to increase the quality of care, since, among other factors, it directly influences the adherence of the individual to the treatment of hypertension, so that, from there, he believes in the guidelines received and takes the necessary care to control the disease ${ }^{(17)}$.

Qualified listening in the reception is essential for the establishment of the bond, it is understood as one of the pillars of therapeutic action, fundamental for an assistance with a view to completeness $^{(18)}$. The recommendation is that there be individualized follow-up of the elderly with hypertension, understanding that the context of each one and how they live with the disease are essential elements for care that intends to keep blood pressure levels under control and promote quality of life ${ }^{(19)}$.

In this sense, even though the contributions of the FHS to the effective change of attention model have not yet occurred as expected, it is possible to verify concrete changes in the relations, once the professionals come to understand the user in its entirety, in its context family and social and in different situations lived in the daily life, distinct from the other modes of care that coexist in the health system ${ }^{(15)}$.

The academic training based on the biomedical model was characterized in nursing workers' statement, as an element that makes it difficult to care for the patient with HBP. A similar situation was also found in other studies conducted at the FHS, showing that this situation is repeated in different places of the Brazilian reality ${ }^{(23-25)}$.

The professional training based on the biomedical paradigm is related to a way of thinking conjugated to Cartesian practice: they know only as a viable possibility the use of medicine ${ }^{(4)}$. However, the health care of hypertension in the older adults needs to be determined in its integrality, biopsychosocial and in the preservation of its functionality ${ }^{(7)}$. In this perspective, treatment means caring and dialogue, not just medicating, or excessive intervention on the bodies through tests. For this, it is necessary, on the part of the health professional, besides the technical-scientific preparation, the humanistic, with the appreciation of the subjective dimension of the health of the users ${ }^{(26)}$.

The professionals trained on the basis of the biomedical model present difficulties to understand the process of illness of the individual, because, in their professional performance, they do not consider the concept of Integral Health Care ${ }^{(23)}$.

This fragmented health system is typical of a model of health care aimed at addressing acute conditions, which is a contradiction of Brazilian health, since it presents a chronic illness. This impasse is closely related to the historical hegemony of the socalled medical or biomedical medical model, characterized by the biological and mechanistic conception of the body. According to this conception, health is understood as the absence of disease, valuing only the technicist approach to health care, whose care is predominantly curative ${ }^{(22)}$.

To reverse this model, the health system and services must invest in light relational technologies, focused on the user and their needs ${ }^{(23)}$. Authors explain the importance of continuous interventions for health promotion, prevention of risks for the control of chronic diseases, especially hypertension and diabetes, and strengthening the link through effective communication to obtain knowledge about the reality of these population groups ${ }^{(24)}$.

The FHS proposes a work with collective interventions based on the reception, bond and integrality, with the demand through a dialogic relationship based on the recognition of the user as a historical being, with experiences and experiences that can contribute to changes in the health context. Thus, the principles and guidelines of this strategy presuppose the development of collective practices that are, in essence, privileged practices because they propose a differentiated, integral and interactive care characterized by powerful "spaces" that generate autonomy in the work process ${ }^{(22-25)}$.

It is important to highlight that the change in search of integrality requires the disruption of the biomedical model through policies of prioritization of Family Health, of change in the formation of human resources ${ }^{(6)}$. In addition, the older adult population presents physiological alterations and pathologies that occurs with increasing dependence. From a theoretical point of view, this requires a deepening of concepts, such as levels of prevention, palliative care, support and social support. In practice, nursing professionals can work with older adults, their families/caregivers, facing together situations of loss of functional capacity and death ${ }^{(27)}$.

Specific concepts of gerontology such as geriatric syndromes, rehabilitation, fragility, independence (ability to perform tasks without help) and autonomy (self-determination ability) are not usually found in undergraduate content, but are operational for the proposition of adequate behaviors ${ }^{(28)}$. Interventions based on such a frame extrapolate the biomedical, hegemonic model. Focusing on disease, the biomedical model subordinates social, economic, and subjective aspects in determining the healthdisease process and is characterized by reductionism, by treating complex phenomena as simple primary principles, and by mind-body dualism ${ }^{(29)}$.

In the respondents' statements, the disease-centered care was also mentioned as a barrier to care for the older adult with hypertension. On the other hand, in order to overcome it, the literature points as a strategy the patient-centered care as a new clinical method that has two main components: one refers to the care of the person, identifying their ideas and emotions about the illness and the response to them; and the second relates to identifying common goals between health professionals and 
patients about the disease and its approach, sharing decisions and responsibilities ${ }^{(30)}$.

The benefits of patient-centered attention to the traditional, disease-centered biomedical model are many, including increased patient satisfaction, greater adherence to treatment and better response to therapy, greater health professional satisfaction, fewer processes for errors, greater efficiency of care, reducing the number of complementary exams and referrals to specialists, with consequent lower costs for the health system and for the patient ${ }^{(30)}$.

With a view to maintaining the functionality of hypertension in older adults, it is essential to optimize the management of chronic conditions based on multidimensional strategies anchored in the concept of health care integrality and with the theoretical references related to person centered care ${ }^{(31)}$, which is not always observed. Studies also show a care practice aimed at responding to the conditions and events resulting from chronic conditions exacerbations, in a fragmented, episodic and reactive way ${ }^{(4,9,15)}$ , becoming barriers in the consolidation of the quality of care provided, especially in Primary Care ${ }^{(32)}$.

In the present study, it was identified through the speeches, the difficulties of nursing workers to guarantee a care centered in the person, expressed by possible difficulties in incorporating in practice non-clinical aspects of chronic care, such as the implementation of self-care supported. However, the person-centered care is one of the key elements to ensure a high quality of care, being considered by the Pan American Health Organization a fundamental and innovative strategy in the care of people with chronic health problems, once once diagnosed the condition chronic hypertension, such as hypertension, the person will need to deal daily with this disease and, consequently, self-care will be a task for the whole life of this individual, including relatives ${ }^{(7)}$.

In this sense, FHS nursing workers should realize that their role in the integral care of elderly people with HBP goes far beyond the exchange of income and guidelines on care with food, environment, and blood pressure. They should seek an overall assessment of that individual, and, from there, provide the necessary care and referrals. However, this extended care is only possible with skills in the geronto-geriatric area(21).

On this difficulty in providing comprehensive care to the elderly with HBP, they also report, as an influential factor, the still incipient knowledge of the graduation. Managers must pay attention to the expressed need by nursing workers to be trained in other care areas, expanding in addition to women's health and child health, which are important areas of action in the FHS, but do not cover care in its entirety, since the strategy aims at caring for the family as a whole ${ }^{(24)}$.

Thus, it is evident the need for managers to reflect and optimize the operationalization of public health policies directed to the elderly, programming and conducting targeted and specific training for care in the elderly and expanding financial resources to improve the actions in this area. area ${ }^{(27)}$.

In addition to promoting greater knowledge about the health of the elderly, skills are useful tools to change the profile of the elderly attended by the FHS, in that they stimulate a new vision of the professionals about what care comes to being-elderly ${ }^{(30)}$.

In addition, another aspect addressed in the interviewees' statements as an obstacle to the care of the elderly with HBP was the lack of intersectorality. This refers to the articulation between the various services and actions related to health care so that, regardless of where they are provided, they are synchronized and aimed at achieving a goal common to all. In addition, it is based on the existence of integrated actions between service providers of different levels or within the same level, as in the case of basic care, so that different interventions are perceived and experienced by the user on an ongoing basis, their health care needs and compatible with their personal expectations ${ }^{(32)}$.

The approach to public policy makers would entail the adoption and formulation of comprehensive and integrated public health policies and actions, supported by intersectoral actions, taking into account the various life cycles, local conditions and needs ${ }^{(5)}$.

It is important to make progress in intersectoral actions in order to mobilize and make the issue of coping with hypertension in the processes of organization of services and of health in general. The challenges and limits related to intersectoral activities that seek to advance the goals of the Strategic Action Plan for Coping with Chronic Noncommunicable Diseases in Brazil, 2011-2022, will be minimized with the joint involvement of civil society, health entities, universities, health councils, NGOs and SUS users. The participation of civil society is vital if this agenda is to become a priority ${ }^{(6)}$.

Take, for example, the reduction of the sedentary lifestyle in the elderly population, which requires essential measures to increase levels of physical activity, such as: the creation of adequate and safe public spaces, the organization of urban space for walking and / or on bicycles, investing in public safety, lighting, among other aspects of urban planning. In this way, it moves from the exclusive focus on the individual desire and decision to engage in corporal practices to analyze the conditions that facilitate or not the election of a more or less sedentary way of life ${ }^{(5)}$.

Likewise, access to food implies not only individual choices, but, fundamentally, integrated public policies, from: educational actions; encouraging the production, distribution and marketing of adequate food; timely legislation on salt, sugar, trans fats; nutritional information in industrialized products; regulation of the content of advertisements ${ }^{(9)}$.

The author points out that the integration between different areas and the approach of problems in a creative way for the integral care of elderly people with hypertension through intersectoral actions demands individual, institutional changes and intersectoral actions. It also describes some of the obstacles that such an ambitious construction faces ${ }^{(23)}$. The framework of Higher Education Institutions (HEls), organized in faculties and departments that may not be communicated, can impede the development of an academic culture that develops and shares the work in an intersectoral and interdisciplinary way ${ }^{(15)}$.

Moreover, the formalization of the professions implies demands for exclusive knowledge and skills, which are assigned a social mandate to carry out specific tasks, control of resources and legal responsibility, crystallizing the social and technical division of labor ${ }^{(19)}$.

Finally, the discontinuity of care in the health care network was also identified among nursing workers as an element that makes it difficult to provide assistance to the elderly with HBP in FHS. Although this service has contributed to the access of the population, 
especially to those with greater socioeconomic deficiency, it is also revealed that the axis related to equity of access to all available technology to improve living and health conditions still constitutes utopia, since it is segmented and disjointed inside the public system and the organizational chain of the system as a whole ${ }^{(9)}$.

In this regard, it should be considered that FHS in elderly care with HBP should be incorporated into a network of more complex services, since, in isolation, it is incapable of responding to the health needs of these users ${ }^{(15)}$. In this sense, it is necessary to eliminate the barriers between the different levels of attention, linked by strategies of management, financing and information in functional integration, guided by a flexible and flexible system capable of shared decisions and responsibilities ${ }^{(16)}$.

Although the FHS aims to reorient the health system from basic care, it does not mean that it assigns all the responsibilities and burdens that fall within the three levels of care. In this sense, investment in the development of new skills for the professionals of the basic team will not replace the actions that must be performed at the level of the specialty clinic, laboratories and diagnostic centers, and general and specialized hospitals ${ }^{(18)}$.

The construction of a network of integral attention to the health of the elderly person that causes chronic noncommunicable disease is the biggest challenge because of its complex nature. It demands the supply of various types of services, which require different sources of financing, which must be structured in a regionalized, integrated way, in order to guarantee the longitudinality of care ${ }^{(9)}$. The lack of services with different objectives such as rehabilitation, nursing care, palliative care, care for people with physical and / or mental incapacity makes it difficult to provide longitudinal and caregiver assistance ${ }^{(4)}$.

In addition, the presence of elderly users with HBP in a care network requires dialogue between different health services and levels of care. Hence the importance of capacity building, establishment of reference and counter reference mechanisms, adaptation of risk identification instruments for fragility and functional incapacity (within each level of care, with emphasis on basic care). Each of the services and levels of care must be clear to both the individual and the community of their spectrum of action ${ }^{(9)}$. Thus, the role of FHS in primary and secondary prevention, education and health promotion, identification of the elderly with risk of functional impairment or loss, and the accompaniment of elderly people who are bedridden or incapable of getting around ${ }^{(20)}$ would be more defined.

Disorganization of the network, lack of support structures, lack of integration of existing services and insufficient provision of specialized services (such as day-care centers or day hospitals, medium and long-term care units with specific care for physically or mentally, palliative care units) and support for families and caregivers still incapacitate SUS to provide integrality of care for the older adult ${ }^{(22)}$. The current context, however, already presents the expansion of access to health services, and it is now necessary to discuss the social importance given to the older adult in Brazil, generating the political will to develop the necessary equipment in the system, so as to allow a resolutive and rewarding work of professionals trained to do so ${ }^{(24)}$.

Through the findings, it is important to highlight the important role of nursing workers in caring for elderly people with hypertension as agents of change. Its essence "care" provides spaces of intersubjective encounter between the professional and the person who experiences a chronic health condition so necessary for the development of behavioral attitudes / changes. It is a slow and difficult process for people with chronic conditions, as it involves rethinking the whole routine and adapting the project of life.

In this sense, the nurses' performance has great potential to act according to the presuppositions of chronic care, be it in the nursing consultation, or in individual or collective educational activities, even in mobilization actions in the community. This will be achieved through a critical-reflexive assimilation of knowledge that makes possible the awareness of the new health condition, in an autonomous way. In this context, nursing is capable of rescuing intersubjectivity, involving reflection and action, which allows the other to problematize their situation whose freedom is filling the space previously inhabited by their dependence and in this way discovers how to participate in the transformation of their world in favor of integral health of the human being.

\section{Study limitations}

The study presented as a limitation the fact that it was carried out in only one Sanitary District, which does not mean that the reality found is the same in the other districts of the city investigated.

\section{Contributions of the study to the health area}

Thus, it is reiterated that Nursing is very important to identify and understand the relationships between the different basic needs of hypertension in older adults which is fundamental care for this group. The evaluation of people with this disease involves complex and varied aspects. The important thing is to identify the positive aspects, the limitations and the subjective aspects that interfere in the self-care, so that they result in fundamental nursing care for older adultswith HBP. In addition, it is expected that the present study contributes in the field of health by its interdisciplinary character, considering the need to be known subjective dimensions on health and on the aging process, socially contextualized. It is believed that one of the contributions of this research is to provoke reflection on the health services offered to the elderly under chronic conditions and that local managers and Primary Health Care workers can implant their care practice to benefit the elderly person with HBP assisted in the FHS.

\section{FINAL CONSIDERATIONS}

The present study sought to know how nursing workers perceive the health care provided to older adults with HBP in the FHS. It was observed favorable and unfavorable contents and elements to the provision of health services to older adults with $\mathrm{HBP}$, demonstrating the need to expand this offer in the perspective of a more comprehensive care. In their reports, the workers referred to multiple elements that configure such a scenario of services offered to this age group, of a biological, political and sociocultural nature; and pointed out determinants of this assistance, such as: territorialization, partnerships, the user's link 
with the team, focus of care centered on the disease, academic training based on the biomedical model, lack of intersectoriality and discontinuity of care in the care network.

The limitations of FHS professionals in the care of the elderly with HBP could be minimized through: strategic health planning and better professional qualification in attending to this aging population, requiring a better follow-up of the elderly in chronic conditions and a system of health with emphasis on the personalized service to this clientele, considering their specifics; and, finally, assistance that is committed to improving their quality of life, autonomy and independence.

Regarding the training of the health professional, nursing workers revealed that in undergraduate education there is a certain deficiency in the approach to aging, leaving these professionals unconscious about this problem. In this sense, it is clear the need for greater investments in the training of FHS professionals in the area of gerontology, being essential the permanent education in health aggregated to individual and institutional development.

\section{REFERENCES}

1. Prince MJ, Wu F, Guo Y, Gutierrez Robledo LM, O'Donnell M, Sullivan R, et al. The burden of disease in older people and implications for health policy and practice. Lancet [Internet]. 2015[cited 2017 Dec 03];385(9967):549-62. Available from: https://www.ncbi.nlm.nih.gov/ pubmed/25468153

2. Mendes G, Moraes C, Gomes L. Prevalência de hipertensão arterial sistêmica em idosos no Brasil entre 2006 e 2010. Rev Bras Med Fam Comunidade[Internet]. 2014[cited 2017 Dec 03];9(32):273-8. Available from: https://rbmfc.org.br/rbmfc/article/view/795

3. Nwankwo T, Yoon SS, Burt V, Gu Q. Hypertension among adults in the United States: National Health and Nutrition Examination Survey, 20112012. NCHS Data Brief[Internet]. 2013[cited 2017 Dec 03];(133):1-8. Available from: https://www.ncbi.nlm.nih.gov/pubmed/24171916

4. Ferreira FPC, Bansi LO, Paschoal SMP. Serviços de atenção ao idoso e estratégias de cuidado domiciliares e institucionais. Rev Bras Geriatr Gerontol[Internet]. 2014 [cited 2017 Jan 20];17(4):911-26. Available from: http://www.scielo.br/pdf/rbgg/v17n4/1809-9823-rbgg-17-04-00911.pdf

5. Taddeo PS, Gomes KWL, Caprara A, Gomes AMA, Oliveira GC, Moreira TMM. Acesso, prática educativa e empoderamento de paciente em condições crônicas. Ciênc Saúde Coletiva[Internet]. 2012 [cited 2017 Jan 21];17(11):2923-30. Available from: http://dx.doi.org/10.1590/ S1413-81232012001100009

6. Trentini M, Paim L, Guerreiro D. Condições crônicas e cuidados inovadores em saúde. São Paulo: Editora Atheneu; 2014.

7. Guimarães ML. O cuidado ao idoso em saúde coletiva um desafio e um novo cenário de prática. In: Sousa MCM, Horta NC. Enfermagem em saúde coletiva teoria e prática. Rio de Janeiro: Guanabara Koogan; 2013.

8. Coelho Filho JM. Saúde do Idoso. In: Rouquayrol MZ, Gurgel M. Epidemiologia \& Saúde. Rio de Janeiro: MedBook; 2013.

9. Martins AB, D'Avila OP, Hilgert JB, Hugo FN. Atenção Primária a Saúde voltada as necessidades dos idosos: da teoria à prática. Ciênc Saúde Coletiva [Internet]. 2014[cited 2017 Oct 23];19(8):3403-16.Available from: http://www.scielo.br/pdf/csc/v19n8/1413-8123csc-19-08-03403.pdf

10. Mallmann DG, Galindo Neto NM, Sousa JC, Vasconcelos EMR. Educação em saúde como principal alternativa para promover a saúde do idoso. Ciênc Saúde Coletiva [Internet]. 2015[cited 2017 Oct 23];20(6):1763-72. Available from: http://www.scielo.br/pdf/csc/v20n6/14138123-csc-20-06-1763.pdf

11. Janini JP, Bessler D, Vargas AB. Educação em saúde e promoção da saúde: impacto na qualidade de vida do idoso. Saúde Debate[Internet]. 2015[cited 2017 Oct 23];39(105):480-90. Available from: http://www.scielo.br/pdf/sdeb/v39n105/0103-1104-sdeb-39-105-00480.pdf

12. Bardin L. Analise de Conteúdo. 7a ed. São Paulo: edições 70; 2011.

13. Antunes MJM, Guedes MVC. Integralidade nos Processos Assistenciais na Atenção Básica. In: Garcia TR, Egry EY, organizadores. Integralidade da atenção no SUS e Sistematização da Assistência de Enfermagem. Porto Alegre: Artmed; 2010. p.19-28.

14. Pasternak S. Habitação e saúde. Estud Av[Internet]. 2016 [cited 2017 Mar 22];3(86):51-66. Available from: http://www.scielo.br/pdf/ea/ v30n86/0103-4014-ea-30-86-00051.pdf

15. Simões WMB, Moreira MS. A importância dos atributos: acolhimento, vínculo e longitudinalidade na construção da função de referência em saúde mental na atenção primária à saúde. Enferm Rev[Internet]. 2013 [cited 2017 Apr 10];16(3):223-39. Available from: http://periodicos. pucminas.br/index.php/enfermagemrevista/article/view/12894

16. Pessoa VM, Rigotto RM, Carneiro FF, Teixeira ACA. Sentidos e métodos de territorialização na atenção primária à saúde. Ciênc Saúde Coletiva[Internet]. 2013 [cited 2017 Apr 25];18(8):2253-62. Available from: http://www.scielo.br/pdf/csc/v18n8/09.pdf

17. Porto AR, Dall'Agnol CM. Analysis of nursing proactivity in a public university hospital. Acta Paul Enferm [Internet]. 2016 [cited 2018 May 14];29(5):603-9. Available from: http://www.scielo.br/pdf/ape/v29n5/en_1982-0194-ape-29-05-0603.pdf

18. Teixeira C, Silva CCS, Bernardes GS, Sá NPP, Prado OS. O vínculo entre usuários e equipes em duas unidades de saúde da família em um município do Estado do Rio de Janeiro. Rev APS [Internet]. 2013 [cited 2017 Apr 10];16(4):444-54. Available from: https://aps.ufjf.emnuvens. com.br/aps/article/view/1725/768

19. Baratieri T, Mandu ENT, Marcon SS. Compreensão de enfermeiros sobre vinculo e longitudinalidade do cuidado na estratégia saúde da família. Cienc Enferm[Internet]. 2012 [cited 2017 Dec 10];18(2):11-22.Available from: http://dx.doi.org/10.4067/S0717-95532012000200002 
20. Veras RP. Prevenção de doenças em idosos: os equívocos dos atuais modelos. Cad Saúde Pública[Internet]. 2012 [cited 2017 Dec 06];28(10):1834-40. Available from: http://www.scielo.br/pdf/csp/v28n10/03.pdf

21. Valcarenghi RV, Lourenço LFL, Siewert JS, Alvarez AM. Nursing scientific production on health promotion, chronic condition, and aging. Rev Bras Enferm[Internet]. 2015 [cited 2017 Apr 25];68(4):618-25. Available from: http://www.scielo.br/pdf/reben/v68n4/en_0034-7167reben-68-04-0705.pdf

22. Seixas CT, Merhy EE, Baduy RS, Slomp Jr H. La integralidad desde la perspectiva del cuidado em salud: una experiência del Sistema Único de Salud en Brasil. Salud colect[Internet]. 2016[cited 2017 Sep 30];12(1):113-23. Available from: https://www.scielosp.org/pdf/scol/2016.v12n1/113-123/es

23. Andrade RS, Caldas LBSN, Falcao MLP, Goes PSA. Processo de trabalho em Unidade de Saúde da Família e a educação permanente. Trab Educ Saúde[Internet]. 2016 [cited 2017 Sep 11];14(2):505-21. Available from: http://www.scielo.br/pdf/tes/v14n2/1678-1007-tes-1981-7746sip00108.pdf

24. Fertonani HP, Pires DEP, Biff D, Scherer MDA. The health care model: concepts and challenges for primary health care in Brazil. Ciênc Saúde Coletiva[Internet]. 2015 [cited 2017 Oct 25];20(6):1869-78. Available from: http://www.scielo.br/pdf/csc/v20n6/en_1413-8123csc-20-06-1869.pdf

25. Yoshida VC, Andrade MGG. O cuidado à saúde na perspectiva de trabalhadores homens portadores de doenças crônicas. Interface (Botucatu) [Internet].2016 [cited 2017 Dec 05];20(58):597-610. Available from: http://www.redalyc.org/articulo.oa?id=180146193007

26. Conte M, Cruz CW, Silva CG, Castilhos NRM, Nicolella ADR. Convergence and Non-Convergence: stories of elderly who have attempted suicide and the Integrated Care System in Porto Alegre/RS, Brazil. Ciênc Saúde Coletiva [Internet]. 2015 [cited 2017 Dec 02];20(6):1741-9. Available from: https://www.ncbi.nlm.nih.gov/pubmed/26060952

27. Pinheiro GML, Alvarez AM, Pires DEP. A configuração do trabalho da enfermeira na atenção ao idoso na Estratégia de Saúde da Família. Ciênc Saúde Coletiva[Internet]. 2012 [cited 2017 Dec 05];17(8):2105-15. Available from: http://www.scielo.br/pdf/csc/v17n8/21.pdf

28. Neves RG, Duro SMS, Flores TR, Nunes BP, Costa CS, Wendt A, et al. Atenção oferecida aos idosos portadores de hipertensão: pesquisa Nacional de Saúde, 2013. Cad Saúde Pública[Internet]. 2017[cited 2017 Oct 23];33(7):e00189915. Available from: http://www.scielo.br/pdf/ csp/v33n7/1678-4464-csp-33-07-e00189915.pdf

29. Jardim LMSSV, Jardim TV, Souza WKSB, Pimenta CD, Sousa ALL, Jardim PCBV. Tratamento multiprofissional da hipertensão arterial sistêmica em pacientes muito idosos. Arq Bras Cardiol [Internet]. 2017 [cited 2017 Oct 23];108(1):53-9. Available from: http://dx.doi.org/10.5935/ abc.20160196

30. Malta DC, Morais Neto OL, Silva Jr JB. Presentation of the strategic action plan for coping with chronic diseases in Brazil from 2011 to 2022. Epidemiol Serv Saúde [Internet]. 2011 [cited 2017 Oct 22];20(4):425-38. Available from: http://scielo.iec.gov.br/pdf/ess/v20n4/v20n4a02. pdf

31. Agreli HF, Peduzzi M, Silva MC. Patient centred care in interprofessional collaborative practice. Interface (Botucatu) [Internet]. 2016[cited 2017 Dec 02];20(59):905-16. Available from: http://www.scielo.br/pdf/icse/v20n59/en_1807-5762-icse-1807-576220150511.pdf

32. Rodrigues LBB, Silva PCS, Peruhype RC, Palha PF, Popolin MP, Crispim JA, et al. Primary Health Care in the coordination of health care networks: an integrative review. Ciênc Saúde Coletiva [Internet]. 2014 [cited 2017 Dec 02];19(2):343-52. Available from: http://www.scielo. $\mathrm{br} / \mathrm{pdf} / \mathrm{csc} / \mathrm{v} 19 \mathrm{n} 2 / 1413-8123-\mathrm{csc}-19-02-00343 . \mathrm{pdf}$ 